\title{
A Multicommuted Flow Analysis Method for the Photometric Determination of Amoxicillin in Pharmaceutical Formulations using a Diazo Coupling Reaction
}

\author{
Sueny K. B. Freitas, ${ }^{a}$ Valdinete Lins da Silva, ${ }^{b}$ Alberto N. Araújo, ${ }^{c}$ Maria Conceição B. S. \\ M. Montenegro, ${ }^{c}$ Boaventura F. Reis ${ }^{d}$ and Ana Paula S. Paim $*$,a \\ ${ }^{a}$ Departamento de Química Fundamental, Universidade Federal de Pernambuco, \\ Av. Prof. Luiz Freire, s/n, Cidade Universitária, 50740-550 Recife-PE, Brazil \\ ${ }^{b}$ Departamento de Engenharia Química, Universidade Federal de Pernambuco, \\ Av. Prof. Artur de Sá, s/n, Cidade Universitária, 50740-521 Recife-PE, Brazil \\ 'Faculdade de Farmácia, Universidade do Porto, Rua Aníbal Cunha, 164, 4099-030 Porto, Portugal \\ ${ }^{d}$ Centro de Energia Nuclear na Agricultura, Universidade de São Paulo, \\ CP 96, 13400-970 Piracicaba-SP, Brazil
}

\begin{abstract}
Neste trabalho foi proposto um método de análise em fluxo por multicomutação para a determinação de amoxicilina em formulações farmacêuticas. O método proposto é baseado na reação de diazotização da $o$-nitroanilina com amoxicilina em meio alcalino, produzindo um composto amarelo que foi monitorado em $435 \mathrm{~nm}$. As características do método foram: faixa linear de 25 até $400 \mathrm{mg} \mathrm{L}^{-1}$ de amoxicilina, limite de detecção de $5,1 \mathrm{mg} \mathrm{L}^{-1}$, frequência analítica de 50 determinações por hora e desvio padrão relativo inferior a 3,9\% $(\mathrm{n}=10)$ para uma amostra típica de $100 \mathrm{mg} \mathrm{L}^{-1}$ amoxicilina. Para verificar a exatidão do método, as amostras foram analisadas empregando um método independente e aplicando-se o teste- $t$ pareado não houve diferença significativa no nível de confiança de $95 \%$.
\end{abstract}

A multicommuted flow analysis method for the spectrophotometric determination of amoxicillin in pharmaceutical formulations is reported. The proposed method is based on the reaction of diazotised $o$-nitroaniline with amoxicillin in an alkaline medium, producing a yellow compound that was monitored at $435 \mathrm{~nm}$. The main features of the method were: a linear relationship with amoxicillin concentration ranging from 25 to $400 \mathrm{mg} \mathrm{L}^{-1}$; a detection limit of $5.1 \mathrm{mg} \mathrm{L}^{-1}$; an analytical throughput of 50 determinations per hour; and a relative standard deviation lower than $3.9 \%$ for a typical amoxicillin sample with concentration of $100 \mathrm{mg} \mathrm{L}^{-1}(\mathrm{n}=10)$. To verify the accuracy of the method, samples were also analyzed employing an independent method, and applying the paired $t$-test to the results no significant difference at the $95 \%$ confidence level was observed.

Keywords: amoxicillin, multicommuted flow analysis, photometry, diazo coupling reaction, $o$-nitroaniline

\section{Introduction}

Amoxicillin, or hydroxyl ampicillin, is a phenolic $\beta$-lactam antibiotic with significant activity against both Gram-positive and Gram-negative bacteria. ${ }^{1}$ This antibiotic is widely used to treat infectious diseases in humans and animals, and to enhance both growth and yield in agriculture. ${ }^{2}$ Its widespread use, however, has led to a potential health risk,

*e-mail: anaspaim@ufpe.br, paulapaim@pq.cnpq.br since amoxicillin is a class of penicillin and runs the risk of hypersensitivity reactions in some individuals. ${ }^{3}$

The therapeutic importance of amoxicillin requires the development of a sensitive and rapid method for industrial quality control and clinical monitoring. The United States Pharmacopeia (USP) $31^{4}$ suggests a high-performance liquid chromatography (HPLC) method for determination of amoxicillin in pharmaceutical formulations but this method requires large amount of high purity organic solvents, long system stabilization time and special strategy for 
sample preparation. ${ }^{5}$ A comprehensive review of the literature indicates a number of analytical methods for the determination of amoxicillin. These include methods based on spectrophotometry, ${ }^{6-12}$ chemiluminescence, ${ }^{3,13}$ fluorometry, ${ }^{14,15}$ polarography, ${ }^{16}$ and mass spectrometry. ${ }^{17,18}$ Electrophoresis capilar, ${ }^{5,19}$ and HPLC $^{20,21}$ are included when separation techniques are used.

The flow injection analysis (FIA) process has been widely used in order to automation/mechanization of chemical analysis, presenting among its main features versatility, high sampling throughput and minimal requirement of sample manipulation. ${ }^{22}$ These features have been exploited to develop analytical procedures for the determination of amoxicillin in pharmaceutical formulations employing different detection techniques. ${ }^{23-26}$

The multicommutation process ${ }^{27-29}$ has been used as an efficient tool to handle solutions. The system manifold is constituted of a set of solenoid valves, ${ }^{29,30}$ and a peristaltic pump or several solenoid micro-pumps employed to propel the solutions. ${ }^{31-33}$ The manifold, constituted of solenoid valves ${ }^{30}$ or solenoid mini-pumps, ${ }^{31-33}$ is controlled by a microcomputer in order to insert the sample slugs and the reagent solution into the analytical path. This resource was used in order to reduce both reagent consumption and waste generation. This was accomplished without any significant loss of sensitivity and accuracy of results.

The diazo coupling reaction with $o$-nitroaniline resulting in the diazotized $o$-nitroaniline was employed as a chromogenic reagent for the photometric determination of phenolic $\beta$-lactam antibiotics. ${ }^{6}$

To our knowledge no method based on flow injection analysis has been proposed to determine phenolic $\beta$-lactam antibiotics using this reagent. Thus, in this work we intended to develop a method based on multicommuted flow analysis for the photometric determination of amoxicillin in pharmaceutical preparation. The method selected was based on the reaction of diazotized $o$-nitroaniline and amoxicillin in an alkaline medium, producing a yellow compound monitored at $435 \mathrm{~nm}$. The flow system module comprising solenoid valves and a mixing chamber was designed based on the multicommutation process in order to implement the analytical method using the flow-batch approach. ${ }^{29,34}$ Photometric detection was carried out using a homemade LED-based photometer designed to be coupled to a flow-batch chamber.

\section{Experimental}

\section{Reagents and solutions}

All solutions were prepared with analytical grade chemicals. Purified water presenting electric conductivity lower than $0.1 \mu \mathrm{S} \mathrm{cm}^{-1}$ was used throughout. Amoxicillin trihydrate (Sigma, Germany) was used for preparing the working standard solutions without further purification.

A $1000 \mathrm{mg} \mathrm{L}^{-1}$ amoxicillin stock solution was prepared by dissolving $100 \mathrm{mg}$ of solid amoxicillin (Sigma) in $100 \mathrm{~mL}$ water. Working standard solutions with concentrations between 25 to $400 \mathrm{mg} \mathrm{L}^{-1}$ amoxicillin were prepared by dilution of the stock solution.

A $0.75 \mathrm{~mol} \mathrm{~L}^{-1}$ hydrochloric acid solution was prepared by the addition of $37.0 \mathrm{~mL} \mathrm{HCl}$ concentrated (Merck, Germany) to water and the volume was made up to $500 \mathrm{~mL}$. A $1.5 \mathrm{~mol} \mathrm{~L}^{-1}$ sodium hydroxide solution was prepared by dissolving $15.0 \mathrm{~g} \mathrm{NaOH}$ (Merck) in $250 \mathrm{~mL}$ water. A $3.0 \% \mathrm{~m} / \mathrm{v}$ sodium nitrite solution was prepared by dissolving $7.5 \mathrm{~g} \mathrm{NaNO}_{2}$ (Vetec, Brazil) in $250 \mathrm{~mL}$ water. A $1.0 \mathrm{mg} \mathrm{mL}^{-1} o$-nitroaniline solution was prepared by dissolving $100 \mathrm{mg} o$-nitroaniline (Fluka, Switzerland) in $0.75 \mathrm{~mL}$ of a $0.75 \mathrm{~mol} \mathrm{~L}^{-1} \mathrm{HCl}$ solution. After dissolution, the volume was completed to $100 \mathrm{~mL}$ with water.

\section{Pharmaceutical formulations}

The following pharmaceutical preparations were analyzed: Amoxicillin generic, Amoximed, Amoxina, Neo Moxilin, and Ocylin. All samples were in capsule form, containing 100 or $400 \mathrm{mg}$ of amoxicillin per capsule.

The contents of 10 capsules of each drug were homogenized and 100 or $400 \mathrm{mg}$ of the powder was dissolved in water, the solution was stirred during $15 \mathrm{~min}$ and transferred into each $100 \mathrm{~mL}$ calibrated flask.

\section{Instrumentation}

The equipment set up consisted of a microcomputer equipped with an electronic interface card (PCL711S, American Advantech Corp., San Jose, CA, USA), and running with a software written in Quick BASIC 4.5; an IPC4 Ismatec peristaltic pump furnished with a Tygon pumping tube; three three-way solenoid valves (161T031, NResearch, West Caldwell, NJ, USA); one double pinch solenoid valve (NResearch, 161P011); two solenoid micro-pumps (Biochem valve, 090SP, Morris County, NJ, USA), with a nominal volume of $8 \mu \mathrm{L}$ per stroke; a flow line of polyethylene tubing $(0.8 \mathrm{~mm}$ i.d.); an electronic interface with power and current intensity sufficient to drive the valves and micro-pumps, ${ }^{29-33}$ a homemade reaction chamber; two glass-cylinders, $20 \mathrm{~mm}$ long with a diameter of $2.0 \mathrm{~mm}$; one blue LED $(\lambda=435 \mathrm{~nm})$; a photodiode (Burr Brown $^{\odot}$, OPT301, Tucson, AZ, USA); transistor BD547; and resistors. 


\section{The flow system and the photometer}

The diagram of the proposed setup is shown in Figure 1. The reaction chamber (Rch) was machined from a Teflon block and its form was similar to that which had been used in an earlier work..$^{29}$ Comprised of a cylindrical hole perforated at the longitudinal axis of the Teflon block with a $10 \mathrm{~mm}$ inner diameter and a $40 \mathrm{~mm}$ height. The radiation beam $\left(f_{1}\right)$ emitted by the LED $\left(D_{1}\right)$ crossed the reaction chamber $(\mathrm{Rch})$ towards the photodiode $\left(\mathrm{D}_{2}\right)$.

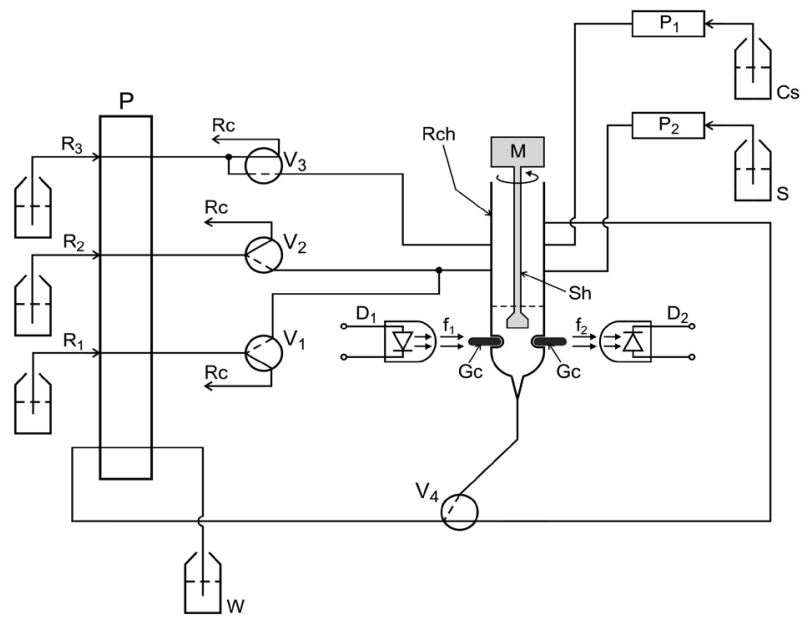

Figure 1. Diagram of the flow system. $\mathrm{S}=$ sample; $\mathrm{Cs}=$ washing fluid (water); $\mathrm{R}_{1}=$ sodium nitrite solution $(3.0 \% \mathrm{~m} / \mathrm{v}), 1.0 \mathrm{mg} \mathrm{mL}^{-1}$, flow rate $1.0 \mathrm{~mL} \mathrm{~min}^{-1}$; $\mathrm{R}_{2}=$ ortho-nitroaniline solution, $1.0 \mathrm{mg} \mathrm{mL}^{-1}$, flow rate $1.0 \mathrm{~mL} \mathrm{~min}^{-1} ; \mathrm{R}_{3}=$ sodium hydroxide solution, $1.5 \mathrm{~mol} \mathrm{~L}^{-1}$, flow rate $1.0 \mathrm{~mL} \mathrm{~min}^{-1} ; \mathrm{P}=$ peristaltic pump; $\mathrm{V}_{1}, \mathrm{~V}_{2}$ and $\mathrm{V}_{4}=$ three-way solenoid valves; $\mathrm{V}_{3}=$ double pinch solenoid valve; $\mathrm{P}_{1}$ and $\mathrm{P}_{2}=$ solenoid micro-pumps $\mathrm{Rch}=$ reaction chamber; $\mathrm{M}=$ mini-motor, $12 \mathrm{~V} \mathrm{DC} ; \mathrm{Sh}=$ PVC mixing stem; $\mathrm{D}_{2}=$ photodetector; $\mathrm{D}_{1}=$ light emitting diode (LED), $\lambda=435 \mathrm{~nm}$; $\mathrm{W}=$ waste $\mathrm{f}_{1}$ and $\mathrm{f}_{2}=$ light beams; $\mathrm{Gc}=$ glass cylinders; $\mathrm{Rc}=$ recycle of solutions. The continuous and interrupted lines in the valves symbols indicate the solutions pathway through the valves when each one is switched OFF or ON, respectively.
The electronic diagram of the photometer is shown in Figure 2. The difference in electric potential $\left(\mathrm{S}_{0}\right)$ has a linear relationship to the intensity of the radiation beam $\left(\mathrm{f}_{2}\right)$. Therefore, when a solution in the chamber absorbs radiation, the intensity of the beam $\mathrm{f}_{2}$ becomes lower than that of beam $\mathrm{f}_{1}$. The signal $\mathrm{S}_{0}$ generated by a photodetector is directly related to the variation of the intensity of $f_{2}$.

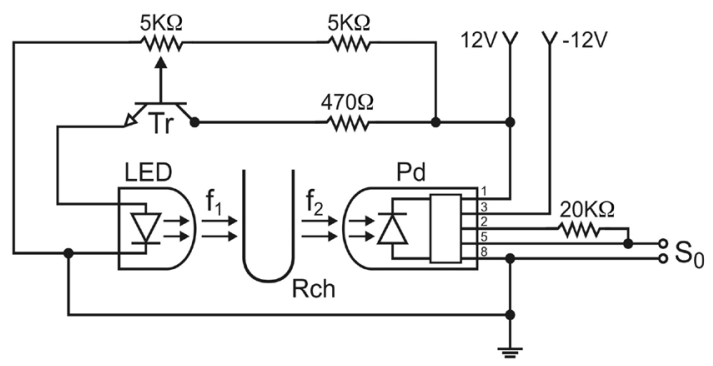

Figure 2. Diagram of the photometer. LED = light emitting diode, $\lambda=450 \mathrm{~nm} ; \mathrm{f}_{1}$ and $\mathrm{f}_{2}=$ light beam coming from the LED; $\mathrm{Pd}=$ photodetector OPT301; $\mathrm{Rch}=$ reaction chamber; $\mathrm{S}_{0}=$ signal output in $\mathrm{mV} ; \mathrm{Tr}=$ transistor BC547.

The micro-pumps $\mathrm{P}_{1}$ and $\mathrm{P}_{2}$ can deliver a solution volume of $8 \mu \mathrm{L}$ per stroke. When they were used, a pulsation frequency of $5 \mathrm{~Hz}$ was maintained to switch them ON/OFF.

The sequence of events carried out by the microcomputer to implement the proposed analytical method under development is shown in Table 1. When the software was run, the values of time and cycles columns were displayed on the screen of the microcomputer, thus their values could be kept current.

Prior to beginning the analytical run, the following steps were implemented by computer: steps one, two and three (Table 1) filling the flow lines with solutions, washing

Table 1. Sequence of events carried out when the software was run

\begin{tabular}{|c|c|c|c|c|c|c|c|c|c|c|}
\hline Step & Event & $\mathrm{V}_{1}$ & $\mathrm{~V}_{2}$ & $\mathrm{~V}_{3}$ & $\mathrm{~V}_{4}$ & $\mathrm{P}_{1}$ & $\mathrm{P}_{2}$ & $\mathrm{M}$ & time & cycles \\
\hline 1 & Filling flow lines & 1 & 1 & 1 & 1 & $1 / 0$ & $1 / 0$ & 0 & $0.1 / 0.1$ & 30 \\
\hline 2 & Washing chamber & 0 & 0 & 0 & 0 & $1 / 0$ & 0 & 1 & $0.1 / 0.1$ & 50 \\
\hline 3 & Emptying chamber & 0 & 0 & 0 & 1 & 0 & 0 & 1 & 50 & - \\
\hline 4 & Inserting water & 0 & 0 & 0 & 0 & $1 / 0$ & 0 & 0 & $0.1 / 0.1$ & 50 \\
\hline 5 & Photometer calibration & 0 & 0 & 0 & 0 & 0 & 0 & 0 & 0 & - \\
\hline 6 & Emptying Chamber & 0 & 0 & 0 & 1 & 0 & 0 & 0 & 50 & - \\
\hline 7 & Inserting Reagent $\mathrm{R}_{1}$ & 1 & 0 & 0 & 0 & 0 & 0 & 0 & 5 & 3 \\
\hline 8 & Inserting Reagent $R_{2}$ & 0 & 1 & 0 & 0 & 0 & 0 & 1 & 2 & \\
\hline 9 & Inserting sample & 0 & 0 & 0 & 0 & 0 & $1 / 0$ & 0 & $0.1 / 0.1$ & 25 \\
\hline 10 & Solutions mixing & 0 & 0 & 0 & 0 & 0 & 0 & 1 & 10 & - \\
\hline 11 & Inserting reagent $R_{3}$ & 0 & 0 & 1 & 0 & 0 & 0 & 1 & 12 & - \\
\hline 12 & Solutions mixing & 0 & 0 & 0 & 0 & 0 & 0 & 1 & 10 & - \\
\hline 13 & Reading signal & 0 & 0 & 0 & 0 & 0 & 0 & 0 & 15 & - \\
\hline
\end{tabular}

The notations " 0 " and " 1 " indicate that the corresponding device is switched OFF or ON, respectively. The notation " $0.1 / 0.1$ " indicate that the time interval for switching ON/OFF the mini-pumps were both of $0.1 \mathrm{~s}$. 
and emptying the reaction chamber (Rch). The computer made these by sending a set of electric pulses through the output port of the PCL 711 S interface card to switch on the solenoid valves and micro-pumps, following the sequence indicated in the Table 1. Afterwards, the photometer calibration (steps 4 and 5) was carried out manually by turning the variable resistor $(5 \mathrm{k} \Omega)$ wired to the base of the transistor (Figure 2) until the signal $\left(\mathrm{S}_{0}\right)$ generated by the photodetector attained $2000 \mathrm{mV}$. This signal was used by the microcomputer as a reference to calculate absorbance. Afterwards, the chamber was emptied by switching ON the valves $\mathrm{V}_{4}$ (step 6). After this step, the system was ready to carry out the analytical run, which was made by performing the sequence of events indicated in Table 1.

The microcomputer read the signal through the analog input of the PCL 711S interface card, which converted the information to digital. After the conversion, the microcomputer calculated the absorbance using the following equation: Absorbance $=-\log \left(\mathrm{S} / \mathrm{S}_{0}\right)$, where $\mathrm{S}$ is the read signal and $S_{0}$ is the reference measurement achieved at the point when the photometer calibration step was performed. The measurement was saved as an ASCII file to allow further treatment. While the analytical run progressed, a plot of the generated signal was displayed on the microcomputer screen to allow its visualization in the real time. After the signal reading event (step 13), the software execution returned to the step 6 in order to empty the chamber, thus beginning the next analytical run.

The variables investigated to develop the analytical method were volumes of sample, and reagents $R_{1}, R_{2}$ and $R_{3}$ inserted into the reaction chamber. After establishing the best operating conditions, a set of pharmaceutical formulation samples were analyzed. To test the accuracy of the assessment, the samples were also analyzed employing an independent method.

\section{Results and Discussion}

In this work, the development of the reaction occurs in two steps: in the first step the reaction of $o$-nitroaniline with sodium nitrite occurs in an acid medium producing the diazo compound. In the second, the diazo compound in alkaline medium coupled with the amoxicillin and produced a compound that was monitored at $435 \mathrm{~nm} .{ }^{6}$ The reaction involving diazotized $o$-nitroaniline as the chromogenic reagent for the determination of amoxicillin is shown below (Scheme 1).

The first assays were carried out using a common flow injection system, and an excess of gas bubbles from the sample zone was observed. This effect made the flow system impractical. To overcome this drawback, the flow

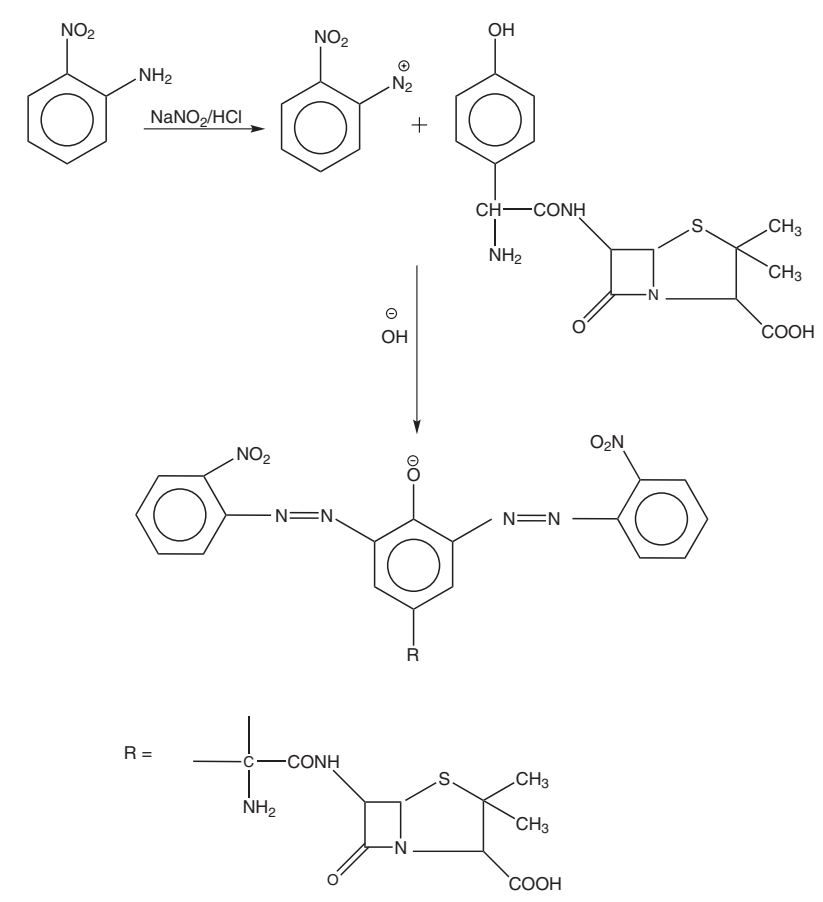

Scheme 1. Reaction of diazo coupling of amoxicillin with $o$-nitroaniline.

system module was re-designed to use the flow-batch approach. ${ }^{29,34,35}$ The open chamber and the efficient mixing obtained using a mini-motor removed the gas bubbles from the bulk of the sample solution in the reaction chamber.

The factors that could affect the reaction of diazotised $o$-nitroaniline and amoxicillin in alkaline medium, and as well as the stability of the compound formed were studied. The control parameters of the flow system designed for the photometric determination of amoxicillin were optimized by an univariate method, which was carried out using a solution $100 \mathrm{mg} \mathrm{L}^{-1}$ amoxicillin.

\section{Effect of the o-nitroaniline solution volume}

The influence of the $o$-nitroaniline $\left(\mathrm{R}_{2}\right)$ solution volume was studied by varying the aliquot volume between 0.15 and $0.67 \mathrm{~mL}$, which was accomplished by varying the time interval to maintain valve $\mathrm{V}_{2}$ (Figure 1) switched $\mathrm{ON}$ between 9.0 and $40.0 \mathrm{~s}$ (Table 2). When solution volumes higher than $0.30 \mathrm{~mL}$ were used, a decrease in sensitivity was observed. This effect could be caused by the dilution of the sample bulk, thus to prevent sensitivity hampering the volume of $0.30 \mathrm{~mL}$ was selected.

\section{Effect of the $\mathrm{NaOH}$ volume}

The effects of the sodium hydroxide solution volume on the analytical signal were investigated by varying the volumes from 0.20 to $0.77 \mathrm{~mL}$, which was carried out by 
Table 2. Effect of the $o$-nitroaniline diazotized solution volume on the analytical signal

\begin{tabular}{lcc}
\hline Volume / $\mathrm{mL}$ & Insertion time / & Absorbance \\
\hline 0.15 & 9.00 & 0.0957 \\
0.17 & 10.0 & 0.0969 \\
0.23 & 14.0 & 0.3163 \\
0.30 & 20.0 & 0.3409 \\
0.38 & 23.0 & 0.2632 \\
0.67 & 40.0 & 0.2397 \\
\hline
\end{tabular}

Results are the average of four consecutive determinations, which were obtained by processing amoxicillin standard solution containing $250 \mathrm{mg} \mathrm{L}^{-1}$.

varying the time interval which kept the valve $\mathrm{V}_{3}$ switched ON from 12.0 to $46.0 \mathrm{~s}$. The results are shown in Table 3 and it may be seen that solution volume of $0.20 \mathrm{~mL} \mathrm{NaOH}$ gave the highest absorbance. Thus this volume was selected for further assays.

Table 3. Effect of the $\mathrm{NaOH}$ solution volume on the analytical signal

\begin{tabular}{lcc}
\hline Volume / $\mathrm{mL}$ & Insertion time / & Absorbance \\
\hline 0.20 & 12.0 & 0.3566 \\
0.37 & 22.0 & 0.3224 \\
0.43 & 26.0 & 0.3157 \\
0.48 & 29.0 & 0.2612 \\
0.77 & 46.0 & 0.2706 \\
\hline
\end{tabular}

Results are the average of four consecutive determinations, which were obtained by processing amoxicillin standard solution containing $250 \mathrm{mg} \mathrm{L}^{-1}$.

\section{Effect of sample volume}

The effect of the sample volume on sensitivity was studied by varying the volume between 0.08 and $0.25 \mathrm{~mL}$, yielding the results shown in Table 4. As we can see, when sample volume varied from 0.08 up to $0.20 \mathrm{~mL}$, the analytical signal underwent a significant increase. When compared with signals related to the volumes 0.20 and $0.25 \mathrm{~mL}$, we can observe that the increase of the signal was less than $5.0 \%$. Therefore, the volume of $0.20 \mathrm{~mL}$ was selected as a compromise between sensitivity, sampling throughput and waste generation.

\section{Optimization of reagents concentration}

The chemical variables studied included different concentrations of hydrochloric acid, sodium hydroxide and sodium nitrite solution. The $o$-nitroaniline solution was prepared in an acid medium. The effect of the hydrochloric acid concentration was investigated with solutions varying from 0.50 to $1.50 \mathrm{~mol} \mathrm{~L}^{-1}$. It may be seen in Table 5 that
Table 4. Effect of sample volume on the analytical signal

\begin{tabular}{lcc}
\hline Volume $/ \mathrm{mL}$ & Number of Pulses & Absorbance \\
\hline 0.08 & 10 & 0.1902 \\
0.12 & 15 & 0.2616 \\
0.16 & 20 & 0.3409 \\
0.20 & 25 & 0.4656 \\
0.25 & 31 & 0.4856 \\
\hline
\end{tabular}

Results are average of four consecutive determinations, which were obtained by processing amoxicillin standard solution containing $250 \mathrm{mg} \mathrm{L}^{-1}$. Volumes of $\mathrm{NaOH}$ and $o$-nitroaniline diazotized solution were maintained at $0.20 \mathrm{~mL}$ and of $0.30 \mathrm{~mL}$, respectively.

acidity of the medium exerts a strong influence on the analytical signal (absorbance). Since a better response was achieved when the acid concentration was $0.75 \mathrm{~mol} \mathrm{~L}^{-1}$, this concentration was selected.

Table 5. Effect of hydrochloric acid concentration

\begin{tabular}{lc}
\hline Concentration / $\left(\mathrm{mol} \mathrm{L}^{-1}\right)$ & Absorbance \\
\hline 0.50 & 0.0395 \\
0.75 & 0.1860 \\
1.00 & 0.0822 \\
1.50 & 0.0747 \\
\hline
\end{tabular}

Results are the average of four consecutive determinations, which were obtained by processing standard amoxicillin standard solution containing $250 \mathrm{mg} \mathrm{L}^{-1}$.

The effect of the sodium hydroxide solution concentration was investigated by varying its concentration from 0.1 to $2.0 \mathrm{~mol} \mathrm{~L}^{-1}$, yielding the results shown in Table 6. As we can see, a better result was obtained when the sodium hydroxide concentration was $1.5 \mathrm{~mol} \mathrm{~L}^{-1}$. Analyzing these results we can observe that reaction development was inhibited, when the concentration of the sodium hydroxide solution was lower or higher than $1.5 \mathrm{~mol} \mathrm{~L}^{-1}$. Considering this observation, $1.5 \mathrm{~mol} \mathrm{~L}^{-1} \mathrm{NaOH}$ solution was selected.

Table 6. Effect of the $\mathrm{NaOH}$ concentration

\begin{tabular}{lc}
\hline Concentration / $\left(\mathrm{mol} \mathrm{L}^{-1}\right)$ & Absorbance \\
\hline 0.1 & 0.0156 \\
0.5 & 0.0295 \\
1.0 & 0.1860 \\
1.5 & 0.2105 \\
2.0 & 0.0404 \\
\hline
\end{tabular}

Results are the average of four consecutive determinations, which were obtained by processing amoxicillin standard solution containing $250 \mathrm{mg} \mathrm{L}^{-1}$.

The concentration of sodium nitrite solution was varied from 1.0 to $3.5 \% \mathrm{~m} / \mathrm{v}$, yielding the results shown in Table 7 . 
These results demonstrate that the increase in absorbance tends to have a constant value for the sodium nitrite solution concentration equal to or higher than $3.0 \% \mathrm{~m} / \mathrm{v}$, so this concentration was selected in order to ensure an excess of reagent in the reaction chamber to guarantee the reaction development.

Table 7. Effect of the $\mathrm{NaNO}_{2}$ concentration

\begin{tabular}{lc}
\hline Concentration $/(\%, \mathrm{~m} / \mathrm{v})$ & Absorbance \\
\hline 1.0 & 0.1607 \\
1.5 & 0.1765 \\
2.0 & 0.1815 \\
3.0 & 0.1860 \\
3.5 & 0.1850 \\
\hline
\end{tabular}

Results are the average of four consecutive determinations, which were obtained by processing amoxicillin standard solution containing $250 \mathrm{mg} \mathrm{L}^{-1}$.

\section{Potential interferences}

Interference studies were carried out in order to investigate the effect of some compounds such as starch, croscarmellose sodium, talc, magnesium stearate, sodium laurilsulphate, silicon dioxide usually found in the amoxicillin formulations. The tolerance limit was taken as the amount that caused a relative error of $\pm 5.0 \%$ in peak height. The results are shown in Table 8. As it can be seen, the tolerance limits were: 100-fold for starch, croscarmellose sodium, magnesium stearate and sodium laurilsulphate; and 5-fold for talc and silicon dioxide.

\section{Figures of merit and accuracy}

The analytical curve was linear within the range of 25 to $400 \mathrm{mg} \mathrm{L}^{-1}$ amoxicillin presenting a typical
Table 8. Tolerance concentration ratio (interferent/amoxicillin) of several species in the determination of amoxicillin ( $200 \mathrm{mg} \mathrm{L}^{-1}$ amoxicillin)

\begin{tabular}{lc}
\hline Foreign species & Tolerated concentration* \\
\hline $\begin{array}{l}\text { Croscarmellose sodium, sodium } \\
\text { laurilsulphate, magnesium stearate } \\
\text { and starch }\end{array}$ & $100^{\mathrm{a}}$ \\
\hline Talc and silicon dioxide & $5^{\mathrm{a}}$ \\
\hline *Data are interferent/analyte concentration ratios, in $\mathrm{mg} \mathrm{L}^{-1} \cdot{ }^{\mathrm{a}}$ Maximum
\end{tabular}
tested ratio.

equation $\mathrm{y}=(0.05762 \pm 0.00536)+(0.00127 \pm 0.00536) \mathrm{x}$ $(\mathrm{R}=0.9997)$, where $\mathrm{y}=$ absorbance and $\mathrm{x}=\mathrm{mg} \mathrm{L}^{-1}$ amoxicillin concentration. The relative standard deviation was $3.9 \%(\mathrm{n}=10)$, estimated by processing a typical sample containing $100 \mathrm{mg} \mathrm{L}^{-1}$ amoxicillin. Other favorable characteristics include: a reagent consumption of $7.5 \mathrm{mg}$ sodium nitrite, $12 \mathrm{mg}$ sodium hydroxide and $1.0 \mathrm{mg}$ $o$-nitroaniline per determination; a sampling throughput of 50 determinations per hour; a detection limit of $5.1 \mathrm{mg} \mathrm{L}^{-1}$ amoxicillin estimated according to the recommendation of IUPAC ${ }^{36}$ (three times of the blank standard deviation divided by the slope of the analytical calibration curve); and a quantification limit of $17.1 \mathrm{mg} \mathrm{L}^{-1}$ estimated as recommended by IUPAC. ${ }^{36}$

The proposed flow system was applied under optimized conditions to determine amoxicillin in commercial formulations. Aiming at an accurate assessment, samples were also analyzed employing HPLC with a UV-Vis detection method. ${ }^{6}$ The results are shown in Table 9. Applying the paired $t$-test between the results for a $95 \%$ confidence level, it was found that $\mathrm{t}_{0.05}=0.8947$, while the theoretical value is $\mathrm{t}_{0.05}=4.303$. Since the experimental value is lower than the theoretical value, there is no significant difference between results at 95\% confidence level.

Table 9. Amoxicillin determination in pharmaceuticals formulations employing the flow system developed and the reference HPLC method ${ }^{4}$

\begin{tabular}{|c|c|c|c|c|c|}
\hline \multirow{2}{*}{ Sample } & \multicolumn{3}{|c|}{ Amoxicillin / $\left(\mathrm{mg} \mathrm{L}^{-1}\right)^{\mathrm{a}}$} & \multicolumn{2}{|c|}{ Error / (\%) } \\
\hline & Label value & Proposed procedure & HPLC & $\mathrm{Er}_{1}$ & $\mathrm{Er}_{2}$ \\
\hline Generic & 104.3 & $128.3 \pm 5.4$ & $133.4 \pm 6.1$ & 23 & -4 \\
\hline Amoximed & 93.4 & $125.7 \pm 10.0$ & $119.0 \pm 13.2$ & 35 & 6 \\
\hline Amoxina & 100.7 & $113.5 \pm 7.3$ & $142.0 \pm 12.8$ & 13 & -20 \\
\hline Amoxina & 402.8 & $390.4 \pm 2.6$ & $479.0 \pm 41$ & -3 & -18 \\
\hline Neomoxilin & 102.0 & $118.8 \pm 2.7$ & $124.0 \pm 6.7$ & 16 & -4 \\
\hline Neomoxilin & 408.4 & $390.5 \pm 12.5$ & $444.0 \pm 11.0$ & -4 & -12 \\
\hline Ocylin & 99.4 & $116.4 \pm 5.1$ & $140.0 \pm 23.5$ & 17 & -17 \\
\hline Ocylin & 397.4 & $429.2 \pm 4.1$ & $449.0 \pm 14.3$ & 8 & -4 \\
\hline
\end{tabular}

${ }^{a}$ Mean \pm standard deviation; $\mathrm{Er}_{1}$ : relative error of proposed system $v s$. label value; $\mathrm{Er}_{2}=$ relative error of proposed flow system $v s$. HPLC method. 


\section{Conclusions}

The use of the flow-batch approach avoided the drawback that would be caused by the gas bubbles entering into the sample bulk. Its implementation employing the multicommutation process made it possible to obtain an analytical method simple to operate, with high sensitivity, low consumption of the sample and the reagents, high throughput, accuracy and precision.

The long-term stability of the proposed setup is satisfactory. This was ascertained by running the process several days for a time period of at least of $3 \mathrm{~h}$. No significant variations of baseline and noise level were observed. In this sense, we can affirm that the proposed setup together with the proposed method could be employed to carry out large scale analysis.

\section{Acknowledgments}

Financial support from, CAPES/GRICES, FACEPE and CNPq is gratefully acknowledged. The authors are grateful to Severino Granjeiro Junior (LAFEPE and UFPE) to help in HPLC analyses.

\section{References}

1. Remers, W. A.; Delgado, J. N.; Wilson and Gisvold's Textbook of Organic Medicinal and Pharmaceutical Chemistry, $9^{\text {th }}$ ed., J. B. Lippincott: New York, 1991.

2. Gilman, A. G.; Goodman, L. S.; Gilman, A. Z.; Goodman and Gilman's, the Pharmacological Basis of Therapeutics, $9^{\text {th }}$ ed., McGraw-Hill: New York, 1995.

3. Li, Y.; Lu, J.; Luminescence 2006, 21, 251.

4. USP 31; The United States Pharmacopeia, $31^{\text {st }}$ ed., Rockville, 2008.

5. Pajchel, G.; Pawlowski, K.; Tyski, S.; J. Pharm. Biomed. Anal. 2002, 29, 75.

6. Salem, H.; Saleh, G. A.; J. Pharm. Biomed. Anal. 2002, 28, 1205 .

7. Salem, H.; Anal. Chim. Acta 2004, 515, 333.

8. Belal, F.; El- Kerdawy, M. M.; El-Ashry, S. M.; El-Wasseef, D. R.; Farmaco 2000, 55, 680.

9. Pasamontes, A.; Callao, M. P.; Anal. Chim. Acta 2004, 515, 159.

10. Li, Q.; Yang, Z.; Anal. Lett. 2006, 39, 763.

11. Fatibello-Filho, O.; Vieira, H. J.; Ecl. Quim. 2008, 33, 47.

12. Suarez, W. T.; Madi, A. A.; Figueiredo-Filho, L. C. S.; Fatibello-Filho, O.; J. Braz. Chem. Soc. 2007, 18, 1215.

13. Liu, W.; Zhang, Z.; Liu, Z.; Anal. Chim. Acta 2007, 592, 187.

14. Muñoz de La Peña, A.; Acedo-Valenzuela, M. I.; EspinosaMansilla, A.; Sánchez-Maqueda, R.; Talanta 2002, 56, 635.
15. Bebawy, L. I.; El Kelani, K.; Abdel Fattah, L.; J. Pharm. Biomed. Anal. 2003, 32, 1219.

16. Gaber, A. A. A.; Ghandour, M. A.; El-Said, H. S.; Anal.Lett. 2003, 36, 1245.

17. Li, B.; Zhang, T.; Xu, Z.; Fang, H. H. P.; Anal. Chim. Acta 2009 , 645, 64.

18. Kantiani, L.; Farré, M.; Sibum, M.; Postigo, C.; López de Alda, M.; Barceló, D.; Anal. Chem. 2009, 81, 4285.

19. Santos, S. M.; Henriques, M.; Duarte, A. C.; Esteves, V. I.; Talanta 2007, 71, 731 .

20. Benito-Peña, E.; Urraca, J. L.; Moreno-Bondi, M. C.; J. Pharm. Biomed. Anal. 2009, 49, 289.

21. Liu, H.; Wang, H.; Sunderland, V. B.; J. Pharm. Biomed. Anal. 2005, 37, 395.

22. Al-Momani, I. F.; Anal. Lett. 2004, 37, 2099.

23. Ruiz-Medina, A.; Fernandez-de Cordova, M. L.; Diaz, A. M.; Anal. Lett. 1999, 32, 729.

24. Chivulescu, A. I.; Danet, A. F.; Kalinowski, S.; Rev. Chim. 2005, 56,695

25. Altiokka, G.; Can, N. O.; Aboul-Enein, H. Y.; J. Liq. Chromatogr. Relat. Technol., 2007, 30, 1333.

26. Molina-Garcia, L.; Llorent-Martinez, E. J.; Fernandez-de Cordova, M. L.; Ruiz-Medina, A.; Spectrosc. Lett. 2010, 43, 60.

27. Reis, B. F.; Gine, M. F.; Zagatto, E. A. G.; Lima, J. L. F. C.; Lapa, R. A.; Anal. Chim. Acta 1994, 293, 129.

28. Pires, C. K.; Martelli, P. B.; Reis, B. F.; Lima, J. L. F. C.; Saraiva, M. L. F. S.; J. Autom. Methods Manage. Chem. 2003, 25, 109.

29. Garcia, A. J. C.; Reis, B. F.; J. Autom. Methods Manage. Chem. 2006, Article ID 83247; DOI 10.1155/JAMMC/2006/83247.

30. Feres, M. A.; Reis, B. F.; Talanta 2005, 68, 422.

31. Lavorante, A. F.; Pires, C. K.; Reis, B. F.; J. Pharm. Biomed. Anal. 2006, 42, 423.

32. Meneses, S. R. P.; Marques, K. L.; Pires, C. K.; Santos, J. L. M.; Fernandes, E.; Lima, J. L. F. C.; Zagatto, E. A. G.; Anal. Biochem. 2005, 345, 90.

33. Lavorante, A. F.; Morales-Rubio, A.; de la Guardia, M.; Reis, B. F.; Anal. Bioanal. Chem. 2005, 381, 1305.

34. Honorato, R. S.; Araújo, M. C. U.; Lima, R. A. C.; Zagatto, E. A. G.; Lapa, R. A. S.; Lima, J. L. F. C.; Anal. Chim. Acta 1999, 396, 91.

35. da Silva, M.; dos Anjos, E.; Honorato, R. S.; Pimentel, M. F.; Paim, A. P. S.; Anal. Chim. Acta 2008, 629, 98.

36. Recommendations for the definition, estimation and use of the detection limit, Analyst 1987, 112, 199.

Submitted: May 14, 2010 Published online: September 30, 2010

FAPESP has sponsored the publication of this article. 